
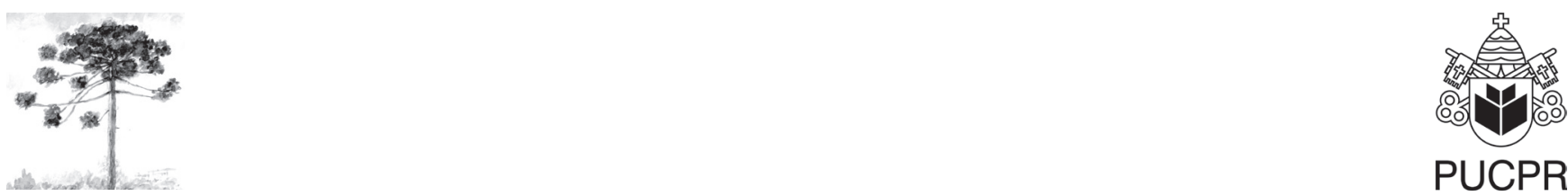

PUCPR

\title{
PERCEPÇÃO DO CONCEITO "ESPÉCIE EXÓTICA” ENTRE AQUARISTAS BRASILEIROS
}

\author{
Perception of the concept "exotic species" among Brazilian aquarists
}

\author{
André Lincoln Barroso de Magalhães
}

Centro Universitário UNA, Programa de Pós-Graduação em Ecologia, Conservação e Manejo de Vida Silvestre, Universidade Federal de Minas Gerais (UFMG), Belo Horizonte, MG - Brasil, e-mail: andrebio@terra.com.br

\section{Resumo}

Para confirmar o grau de desconhecimento do conceito "espécie exótica", realizou-se no período de $1^{\circ}$ de setembro/2007 a $1^{\circ}$ de fevereiro/2008, uma pesquisa utilizando-se 24 comunidades no Orkut distribuídas em 12 para o grupo controle (aquaristas) e 12 para o grupo experimental (ambientalistas). Foi perguntado se sabiam o que é uma espécie exótica de peixe e contabilizou-se no fórum de discussões das comunidades a citação correta do conceito. Houve 1.045 respostas e a maioria dos aquaristas não souberam o significado do conceito $(68,89 \%)$ sendo esse percentual não similar em ambos os grupos $\left(\chi^{2}=342,40 ; \chi^{2}\right.$ crítico $\left.=3,84 ; \mathrm{p}<0,05\right)$. A maioria dos ambientalistas conhece o conceito $(83,87 \%)$ e o citaram corretamente no fórum de discussões $(75,73 \%)$, sendo esses percentuais não similares em ambos os grupos $\left(\chi^{2}=8,88 ; \chi^{2}\right.$ crítico $=3,84 ; p<0,05, \chi^{2}=1.404,50 ; \chi^{2}$ crítico $\left.=3,84 ; p<0,05\right)$. É necessário popularizar o conceito "espécie exótica" no aquarismo com o intuito de se evitar futuras introduções pelo País.

Palavras-chave: Espécie exótica. Orkut. Aquarismo. Introducões.

\section{Abstract}

Cougar (Puma concolor) is a feline found in various ecological zones in Brazil and Americas. In cougar has been reported parasitism by ticks ixodidae and endoparasites of different genera and species. However, researches involving the Brazilian wild fauna are still few. Therefore, this study aimed to evaluate the gastrointestinal parasitism in P. concolor kept in captivity in the central region of Rio Grande do Sul state. Fecal samples of an adult cougar were analyzed by the direct smear method, centrifugal flotation technique with zinc sulfate and kinyon staining method. Mixed infection by 
oocysts of Cryptosporidium sp. and eggs of Trichuris sp. were observed in the samples, besides oocysts of coccidea suggestive of Toxoplasma gondii or Besnoitia sp. Based on the results, it can be concluded that the cougar is a potential host of these parasites, presenting with asymptomatic. However, the true role of the feline in environment related to the spread of these parasites has to be studied.

Keywords: Cryptosporidium. Toxoplasma gondii. Besnoitia. Trichuris.

\section{INTRODUÇÃO}

As questões ambientais no Brasil são tratadas de forma irrelevante e o conceito "espécie exótica" mais ainda, por ser pouco conhecido pelas pessoas (1). De acordo com a União Internacional para a Conservação da Natureza (2), "espécie exótica" é aquela que ocorre em uma área fora de seu limite natural historicamente conhecido, como resultado de dispersão acidental ou intencional, por ação humana.

Segundo Agostinho et al. (3), um dos principais motivos de introduções de espécies exóticas deve-se a motivações culturais ou sentimentais. Ainda segundo esses autores, a motivação sentimental é frequentemente alegada para a soltura de peixes no ambiente, especialmente pelos adeptos da aquariofilia. A facilidade de se encontrar espécies de todo o mundo é um dos aspectos mais relevantes, pois, para consegui-las, basta ir a uma loja especializada em aquarismo. Quando por motivos diversos, o aquarista precisa se desfazer do animal e não quer sacrificá-lo, libera-o no corpo d'água mais próximo acreditando que está lhe fazendo bem, sem saber que vai prejudicar o ambiente receptor.

Esse cenário pode ser revertido por meio de educação ambiental, baseada no esclarecimento adequado do conceito "espécie exótica", pois o entendimento dos aquaristas sobre a correta diferenciação entre "espécie exótica" e "espécie nativa" é fundamental para que não ocorram novas introduções no futuro (4).

Estudos enfocando esta questão são inexistentes no Brasil, sendo assim, a presente comunicação tem como objetivo avaliar o conhecimento de aquaristas de água doce a respeito do conceito "espécie exótica".

Para a realização desta pesquisa, foram utilizadas 24 comunidades da página eletrônica de relacionamentos Orkut, distribuídas em 12 para o grupo controle e 12 para o grupo experimental. Grupo controle: comunidades cujo conceito "espé- cie exótica" presumivelmente não seja familiarizado pelos membros (Aquários e peixes ornamentais: 5.878 membros; Aquarismo: 5.625 membros; Aquariofilia: 5.104 membros; Aquariofilia para todos: 3.082 membros; Aquário hobby: 2.636 membros; Aquários plantados: 2.372 membros; Top Bettas Brasil: 1.417 membros; Aquarismo \& Cia: 1.275 membros; Nature aquarium: 1.069 membros; Kinguio: 979 membros; Aquarismo online: 973 membros; Ciclídeos africanos: 700 membros). Grupo experimental: comunidades cujo conceito "espécie exótica" seja presumivelmente familiarizado pelos membros (Greenpeace Brasil: 104.647 membros; Ecologia: 48.105 membros; WWF Brasil: 28.357 membros; Educação ambiental: 26.157 membros; Meio ambiente urgente: 24.832 membros; SOS meio ambiente: 15.705 membros; SOS mata atlântica: 7.497 membros; Animais selvagens/ Conservação: 4.708 membros; Unidades de conservação: 2.013 membros; Biologia da conservação: 1.424 membros; Biologia Pontifícia Universidade Católica de Minas Gerais: 727 membros; Biologia Universidade federal de Ouro Preto: 340 membros). Utilizou-se questionário com uma pergunta (Você sabe o que é uma espécie exótica de peixe?) e duas respostas ("Sim" e "Não") tendo os membros do Grupo controle e Grupo experimental o período de $1^{\circ}$ de setembro (00:01 horas) de 2007 a $1^{\circ}$ de fevereiro (23:59 horas) de 2008 para responder. Contabilizou-se no fórum de discussões das comunidades a citação correta do conceito "espécie exótica". A proporção das respostas e citações do conceito foi estimada por meio das frequências entre o grupo controle e grupo experimental. Aplicou-se o teste do Qui-quadrado $\left(\chi^{2}\right)$ com o intuito de testar diferenças entre as proporções estabelecidas, e o nível de significância foi de $0,05 \%$.

Um total de 1.045 pessoas (704 do grupo controle e 341 do grupo experimental) respondeu à pergunta. A maioria dos membros do grupo controle (aquaristas) não sabe o significado do conceito "espécie exótica" $(68,89 \%)$, sendo este percentual não similar em ambos os grupos $\left(\chi^{2}=342,40 ; \chi^{2}\right.$ 
crítico $=3,84 ; \mathrm{p}<0,05)$ (Tabela 1). A maioria dos membros do grupo experimental conhece o conceito $(83,87 \%)$ e o citaram corretamente no fórum de discussões $(75,73 \%)$, sendo esses percentuais não similares em ambos os grupos $\left(\chi^{2}=8,88 ; \chi^{2}\right.$ crítico $=3,84 ; \mathrm{p}<0,05, \chi^{2}=1.404,50 ; \chi^{2}$ crítico $=3,84 ; \mathrm{p}$ $<0,05)$ (Tabelas 1 e 2 ).

A falta de conhecimento do grupo controle (aquaristas) sobre o conceito em questão deve-se provavelmente a ausência de enfoque nas grades curriculares dos ensinos infantil, fundamental e médio. O não entendimento do conceito entre aquaristas de água doce é enfatizado por Shibatta et al. (5) e Alves et al. (6) os quais relataram que a presença dos peixes ornamentais exóticos gupi Poecilia reticulata (Peters, 1860), na bacia do Rio Tibagi, Estado de São Paulo, espadinha Xiphophorus hellerii (Heckel, 1848), na bacia do Rio Doce, e japonês Carassius auratus (Linnaeus, 1758), na bacia do Rio Paraíba do Sul, Estado de Minas Gerais, ocorreu em virtude de solturas deliberadas de pessoas ligadas ao 'hobby'.

Em vista do preocupante quadro relacionado à desinformação dos aquaristas sobre o conceito "espécie exótica" associado a um crescente aumento de plantas, invertebrados, peixes e anfíbios de aquário não nativos em território nacional (7), são expostas recomendações para que esta situação se reverta, como: a) promover palestras sobre o significado do conceito "espécie exótica" para lojistas e membros de clubes de aquarismo, b) divulgar o conceito em revistas de aquarismo, c) criar tópicos alertando sobre o conceito "espécie exótica" nas páginas virtuais das comunidades de aquarismo do Orkut e d) inclusão do conceito "espécie exótica" nas grades curriculares dos ensinos infantil, fundamental e médio.

Estas recomendações objetivam evitar futuras introduções de espécies exóticas por aquaristas em todo o País, bem como tentar consolidar corretamente o conceito "espécie exótica", ainda mal compreendido pelos brasileiros.

\section{REFERENNCIAS}

1. Gesisky J. Isto é uma invasão! Terra da Gente. 2004;1(7):69-75.

2. União Internacional para a Conservação da Natureza. Guidelines for protected areas management categories. Gland: UICN; 1994.

TABELA 1 - Comparação das respostas entre os grupos

\begin{tabular}{lccccccccc}
\hline $\begin{array}{l}\text { Você sabe o que é uma } \\
\text { espécie exótica de peixe? }\end{array}$ & \multicolumn{2}{c}{$\begin{array}{c}\text { Grupo } \\
\text { controle } \\
\text { (aquaristas) }\end{array}$} & $\begin{array}{c}\text { Grupo } \\
\text { experimental } \\
\text { (ambientalistas) }\end{array}$ & Total & $\chi^{2}$ & $\begin{array}{c}\chi^{2} \\
\text { crítico }\end{array}$ \\
\cline { 1 - 7 } & FA & FR\% & FA & FR $\%$ & FA & FR\% & & \\
NÃO & 485 & 68,89 & 55 & 16,13 & 540 & 51,67 & 342,40 & 3,84 \\
SIM & 219 & 31,11 & 286 & 83,87 & 505 & 48,33 & 8,88 & 3,84 \\
Total & 704 & 100,00 & 341 & 100,00 & 1.045 & 100,00 & & \\
\hline
\end{tabular}

TABELA 2 - Comparação da citação do conceito entre os grupos

\begin{tabular}{|c|c|c|c|c|c|c|c|c|}
\hline \multirow[t]{3}{*}{$\begin{array}{l}\text { Significado do conceito } \\
\text { "espécie exótica" corretamente } \\
\text { citado nos fóruns de } \\
\text { discussões das comunidades }\end{array}$} & \multicolumn{2}{|c|}{$\begin{array}{c}\text { Grupo } \\
\text { controle } \\
\text { (aquaristas) }\end{array}$} & \multicolumn{2}{|c|}{$\begin{array}{c}\text { Grupo } \\
\text { experimental } \\
\text { (ambientalistas) }\end{array}$} & \multicolumn{2}{|c|}{ Total } & \multirow[t]{2}{*}{$\chi^{2}$} & \multirow[t]{2}{*}{$\begin{array}{c}\chi^{2} \\
\text { crítico }\end{array}$} \\
\hline & $\mathrm{FA}$ & FR\% & FA & $\mathrm{FR} \%$ & FA & $\mathrm{FR} \%$ & & \\
\hline & 25 & 24,27 & 78 & 75,73 & 103 & 100,00 & $1.404,50$ & 3,84 \\
\hline Total & 25 & 100,00 & 78 & 100,00 & 103 & 100,00 & & \\
\hline
\end{tabular}


3. Agostinho AA, Pelicice FM, Júlio Jr HF. Introdução de espécies de peixes em águas continentais brasileiras: uma síntese. In: Rocha O, Espíndola ELG, Fenerich-Verani N, Verani JR, Rietzler AC, editor. Espécies invasoras em águas doces - Estudos de caso e proposta de manejo. São Paulo: Editora Universidade Federal de São Carlos; 2005. p. 13-26.

4. Magalhães ALB, Amaral IB, Ratton TF, Brito MFG. Ornamental exotic fishes in the Glória reservoir and Boa Vista stream, Paraíba do Sul river basin, state of Minas Gerais, southeastern Brazil. Comunicações do Museu de Ciências e Tecnolologia da PUCRS. 2002;15(2):265-78.

5. Shibatta AO, Orsi ML, Bennemann ST, Silva-Souza AT. Diversidade e distribuição de peixes na bacia do rio Tibagi. In: Medri M, Bianchini E, Shibatta AO, Pimenta JA, editor. A bacia do rio Tibagi. Londrina: UEL; 2002. p. 403-23.

6. Alves CBM, Vieira F, Magalhães ALB, Brito MFG. Impacts of non-native fish species in Minas Gerais, Brazil: present situation and prospects. In: Bert MT, editor. Ecological and Genetic Implications of Aquaculture Activities. Dordrecht: Springer; 2007. p. 291-314.

7. Instituto Horus de Desenvolvimento e Conservação Ambiental._Animais exóticos invasores comercializados em pet shops, aviários e lojas de aquário. 2007. [acesso em 20 jun. 2008]. Disponível em: http:/ / www. institutohorus.org.br/pr_pets.htm.

Recebido: 15/07/2007

Received: 07/18/2007

Aprovado: 23/11/2007

Approved: $11 / 23 / 2007$ 